\title{
Microclima de abrigos escamoteadores para leitões submetidos a diferentes sistemas de aquecimento no período de inverno
}

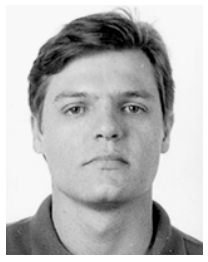

Héliton Pandorfi ${ }^{1}$, Iran J. O. da Silva ${ }^{2}$, Daniella J. de Moura ${ }^{2}$ \& Kelly B.Sevegnani ${ }^{3}$

\author{
${ }^{1}$ NUPEA/ESALQ-USP. Av. Pádua Dias, 11. CP. 09, CEP 13418-900, Piracicaba, SP, Fone (019)3429.4217 Ramal: 241 \\ E-mail: hpandorf@esalq.usp.br (Foto) \\ ${ }^{2}$ ESALQ/USP. E-mail: ijosilva@esalq.usp.br \\ ${ }^{3}$ UNESP. CEP 11900-000, Registro, SP. Fone: (13) 3828-2900. E-mail: kelly@registro.unesp.br
}

Protocolo 101 - 9/6/2003 - Aprovado em 5/4/2004

\begin{abstract}
Resumo: O objetivo desta pesquisa foi avaliar a eficiência dos diferentes sistemas de aquecimento em abrigos escamoteadores para leitões. Foi desenvolvida na sala da maternidade, com 80 animais entre o nascimento e o desmame, adotando-se 4 diferentes sistemas de aquecimento: piso térmico, lâmpada incandescente, resistência elétrica e lâmpada infravermelha. As variáveis ambientais foram registradas no ambiente externo, sala da maternidade e no interior de cada abrigo escamoteador avaliado, ao longo de 18 dias. Para avaliação zootécnica foram registrados ganho de peso diário (GPD) e mortalidade. A análise técnico-econômica foi feita considerando-se o consumo de energia elétrica e o GPD dos animais. $O$ delineamento experimental foi em blocos casualizados com 4 tratamentos e 18 blocos. Os sistemas de aquecimento apresentaram diferenças significativas para temperatura de bulbo seco umidade relativa do ar (UR), e para os índices de conforto, carga térmica radiante e entalpia, sendo que os tratamentos que se mostraram mais adequados, do ponto de vista térmico e técnico-econômico, foram lâmpada incandescente e resistência elétrica.
\end{abstract}

Palavras-chave: conforto térmico, produção animal, suinocultura

\section{Microclimate of creep for piglets submitted to different systems of heating during the winter period}

\begin{abstract}
The general objective of this research was to evaluate the efficiency of different systems of heating in creep for piglets. The experiment was conducted in a commercial swine production farm, located in Elias Fausto city, in the State of São Paulo. The research was developed in the farrowing house, with 80 animals between the birth and weanning, adopting 4 different heating systems: heat mat, standard heating lamp, electrical resistance and infrared lamp. The ambient variables were observed inside and outside the farrowing house and inside each studied creep, during 18 days. For animal production evaluation of daily weight gain and mortality were registered too. The techno-economic analysis was made considering the consumption of electric energy and the weight gained by animals. The statistical design of the experiment was a randomized block design with 4 treatments and 18 blocks. The heating systems presented significant differences for dry bulb temperature, relative humidity, and thermal comfort indexes, radiant thermal load and enthalpy. The treatments standard incandescent bulb and electrical resistance were found to be more adequate from techno-economical point of view.
\end{abstract}

Key words: thermal comfort, animal production, swine production

\section{INTRODUÇÃO}

A suinocultura é uma atividade que exige muita dedicação do criador para alcançar bons índices de produtividade e, em conseqüência, resultados econômicos satisfatórios.
Na suinocultura, um dos maiores problemas relacionados ao conforto térmico e bem-estar animal está na maternidade, onde se tem dois ambientes distintos a serem avaliados, com exigências bem diferenciadas. Na realidade, esta situação é um dos grandes impasses por que passa o produtor, pois em um 
pequeno espaço físico, é notória a necessidade de proporcionar dois microambientes diferentes e, caso isto não ocorra, o desempenho, tanto das matrizes quanto dos leitões, não será satisfatório.

Fatores ambientais externos e o microclima dentro das instalações exercem efeitos diretos e indiretos sobre os suínos em todas as fases de produção e acarretam redução na produtividade, com conseqüentes prejuízos econômicos à exploração suinícola.

Os suínos, por suas características fisiológicas, possuem dificuldades em adaptação às flutuações térmicas ambientais. A faixa de temperatura para seu conforto varia com a idade. Para o leitão, no nascimento a faixa de conforto está entre $32 \mathrm{e}$ $34{ }^{\circ} \mathrm{C}$ e, aos 35 dias, entre 29 e $31{ }^{\circ} \mathrm{C}$, sendo que a temperatura ideal para a matriz está entre 16 e $21^{\circ} \mathrm{C}$ (Perdomo et al., 1987).

A ocorrência de estresse térmico durante a lactação pode afetar negativamente a ingestão de alimento, aumentando a perda de peso e a mobilização de gordura corporal, reduzindo a quantidade de leite produzido, aumentando a taxa respiratória e a temperatura retal e comprometendo, conseqüentemente, o desenvolvimento da leitegada (Thompinks et al., 1967; D’ Arce et al., 1970).

O leitão recém-nascido possui os sistemas de termorregulação e imunitário pouco desenvolvidos, tornando-se sensível às temperaturas ambientais baixas. Nessas condições, o leitão reduz sua atividade motora e, conseqüentemente, diminui a ingestão de colostro, acarretando maior incidência de doenças, maior número de leitões esmagados e alta taxa de refugos na desmama, sendo necessário alguns cuidados especiais. A regra básica é fornecer aos leitões um ambiente limpo, desinfetado, seco e aquecido. Isso significa investir em piso adequado e sistemas de aquecimento (Perdomo et al., 1987).

A temperatura corporal do recém-nascido cai de 1,7 a $6,7{ }^{\circ} \mathrm{C}$, logo após o nascimento. O tempo que o leitão leva para alcançar novamente valores de temperaturas normais $\left(39^{\circ} \mathrm{C}\right)$ depende diretamente da temperatura ambiente, do seu peso corporal e do momento em que começa a amamentar (Bäckström \& Curtis, 1981).

Dentro dos princípios de conforto térmico e bem-estar animal, observam-se as diferentes necessidades ambientais na maternidade, onde se tem dois ambientes distintos a serem avaliados, um para as matrizes lactantes e o outro para os leitões, sendo este um grande problema do produtor de suínos pois, em um pequeno espaço físico, ele é obrigado a proporcionar dois microambientes diferentes e, em caso contrário, o desempenho, tanto das porcas quanto dos leitões, não será positivo.

Desta forma, o objetivo da pesquisa consiste na avaliação do microclima proporcionado por diferentes sistemas de aquecimento para leitões em abrigos escamoteadores.

\section{MATERIAL E MÉTODOS}

A pesquisa foi realizada na granja Querência, propriedade cuja principal atividade é a produção industrial de suínos, localizada no município de Elias Fausto, SP, apresentando latitude de $23^{\circ} 02^{\prime} \mathrm{S}$, longitude de $47^{\circ} 22^{\prime} \mathrm{W}$ e altitude de $580 \mathrm{~m}$, o clima da região é caracterizado como mesotérmico Cwa (tropical de altitude), com temperatura do mês mais frio entre -3 e $18^{\circ} \mathrm{C}$, com inverno seco e temperatura do mês mais quente maior que $22{ }^{\circ} \mathrm{C}$, segundo classificação Köppen (Pereira et al., 2002).

O desenvolvimento da pesquisa foi na sala da maternidade, no período compreendido entre o nascimento e o desmame dos leitões, com duração média de 18 dias, entre os dias 18 de julho a 5 de agosto de 2002 .

Foi avaliada a eficiência de 4 sistemas de aquecimento nos abrigos escamoteadores, constituindo-se os seguintes tratamentos:

Tratamento 1 - abrigo escamoteador equipado com piso térmico de placas pré-moldadas de compósitos biomassa vegetal-cimento aquecido por meio de resistência elétrica, confeccionadas no Laboratório de Ensaios de Materiais, da Faculdade de Engenharia Agrícola da UNICAMP, com dimensões de $0,40 \times 0,50 \mathrm{~m}$, compondo um conjunto de 3 placas por abrigo (378W), de acordo com Rossi et al. (2002).

Tratamento 2 - abrigo escamoteador equipado com lâmpada incandescente de $200 \mathrm{~W}$, fixada na parede de uma das extremidades do abrigo, na altura de $0,50 \mathrm{~m}$ do piso.

Tratamento 3 - abrigo escamoteador equipado com resistência elétrica de $200 \mathrm{~W}$, fixada na parede de uma das extremidades do abrigo, a uma altura de $0,50 \mathrm{~m}$ do piso.

Tratamento 4 - abrigo escamoteador equipado com lâmpada infravermelha de $250 \mathrm{~W}$, fixada na parede de uma das extremidades do abrigo, na altura de 0,50 $\mathrm{m}$ do piso.

Os abrigos escamoteadores possuem as dimensões de $1,50 \mathrm{~m}$ de comprimento por $0,55 \mathrm{~m}$ de largura e $0,65 \mathrm{~m}$ de altura, totalizando uma área de $0,825 \mathrm{~m}^{2}$, e um volume de $0,536 \mathrm{~m}^{3}$. Toda a área de piso foi coberta por uma cama de maravalhas e os sistemas de aquecimento permaneceram acionados durante todo o período experimental.

A sala da maternidade é caracterizada tipologicamente por 23,0 $\mathrm{m}$ de comprimento, 13,5 m de largura e pé direito de 2,8 m, forro revestido com placas de poliestireno, acompanhando a face inferior do telhado. Cobertura com telhas de cerâmica do tipo francesa, sendo que ao longo da sala a instalação apresenta 8 janelas de cada lado, com peitoril de 1,50 m e altura de $1,3 \mathrm{~m}$, totalizando uma área de abertura de janelas de 53,95 $\mathrm{m}^{2}$.

O manejo das cortinas laterais foi realizado em função do ambiente externo à instalação, sendo abertas às 10 horas e fechadas às 16 horas, garantindo a renovação de ar na instalação.

Foram alojadas na sala 34 matrizes em 34 celas parideiras, dispostas no centro de cada baia. As baias possuíam dimensões de 1,7 $\mathrm{m}$ de largura por 2,8 $\mathrm{m}$ de comprimento e 1,2 $\mathrm{m}$ de altura, totalizando $4,76 \mathrm{~m}^{2}$. As celas parideiras e as respectivas matrizes foram selecionadas aleatoriamente, de acordo com o desenho esquemático na Figura 1.

$\mathrm{O}$ estudo foi realizado com animais híbridos threecross (Landrace x Large Whirte x Duroc). Os leitões que fizeram parte do estudo eram de matrizes de mesma ordem de parto, selecionadas com o objetivo de eliminar fatores de interferência, habilidade materna e número de leitões/leitegada. Selecionaramse matrizes de $4^{a}$ ordem, de acordo com a disponibilidade de animais, com previsão de parto coincidente com o período experimental. Cada baia apresentou 10 leitões que, após os 


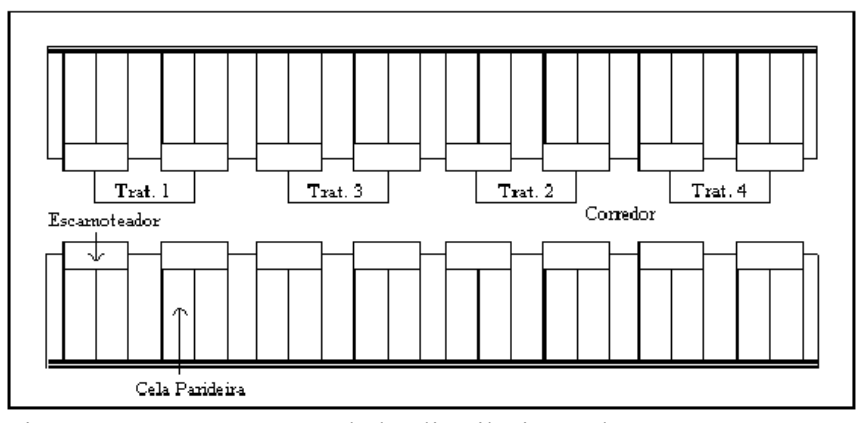

Figura 1. Esquema geral da distribuição dos tratamentos na maternidade

partos, foram remanejados por critério de peso e número de animais/leitegada, de modo que todos os abrigos estudados permaneceram com um número fixo de 10 leitões.

Durante todo o experimento foram monitoradas as variáveis ambientais no abrigo escamoteador, na sala da maternidade e no ambiente externo e registradas, por meio de sensores conectados a uma plataforma automática de coleta de dados, as seguintes variáveis: temperatura de bulbo seco (Ts), temperatura de bulbo úmido $(\mathrm{Tu})$, temperatura de globo negro (Tg) e velocidade do vento (VV).

$\mathrm{O}$ registro dos dados de temperatura foi realizado em intervalos de $15 \mathrm{~min}$, gerando médias horárias durante os 18 primeiros dias de vida dos leitões, período em que os animais permaneceram na maternidade. Os sensores para a obtenção da temperatura eram compostos por uma rede de cabos termopares do tipo $\mathrm{T}$ (cobre-constantan).

A determinação da velocidade do vento (VV) foi realizada manualmente com auxílio de um termo-anemômetro da marca Testo, modelo 405-V1, com intervalo de uma hora, das 7:00 às 18:00 h, a uma altura de $0,20,1,20$ e 2,00 m, no abrigo escamoteador, na sala da maternidade e no ambiente externo, respectivamente.

Nos abrigos escamoteadores os sensores, para determinação da Ts, Tu e Tg, foram acoplados na tampa dos abrigos escamoteadores, distando $0,55 \mathrm{~m}$ do piso. Na sala da maternidade as variáveis ambientais foram registradas no interior da instalação, na região central das baias estudadas, a uma altura de $1,30 \mathrm{~m}$ do piso e, no ambiente externo às instalações, os sensores foram instalados no interior de um abrigo meteorológico, a 1,50 m de altura da superfície, representando o microclima do local.

Para determinação da eficiência térmica em cada tratamento, com os dados de temperatura dos ambientes estudados, foram determinados o índice de temperatura de globo e umidade (ITGU), carga térmica radiante (CTR) e entalpia $(\mathrm{H})$ por meio das seguintes equações:

a) índice de temperatura de globo e umidade (ITGU), proposta por Buffington et al. (1981):

$$
\mathrm{ITGU}=\mathrm{Tg}+0,36 \mathrm{Tpo}-330,08
$$

em que:

$\mathrm{Tg}$ - temperatura de globo negro $(\mathrm{K})$

Tpo - temperatura de ponto de orvalho $(\mathrm{K})$ b) índice de carga térmica radiante (CTR), proposta por Esmay (1982):

$$
\begin{gathered}
\mathrm{CTR}=\tau(\mathrm{TMR})^{4} \\
\mathrm{TRM}=100\left\{\left[2,51(\mathrm{VV})^{0,5}(\mathrm{Tg}-\mathrm{Ts})+\left(\frac{\mathrm{Tg}}{100}\right)^{4}\right]^{0,25}\right\}
\end{gathered}
$$

em que:

TRM - temperatura radiante média $(\mathrm{K})$

$\mathrm{W}$ - velocidade do vento $\left(\mathrm{m} \mathrm{s}^{-1}\right)$

$\mathrm{Tg}$ - temperatura de globo negro (K)

$T s \quad$ - temperatura de bulbo seco $(\mathrm{K})$

$\tau \quad-5,6710^{-8}$ (Constante de Stefan-Boltzmann) $\left(\mathrm{K}^{-4} \mathrm{~W} \mathrm{~m}^{-2}\right)$

c) entalpia ( $\mathrm{kJ} \mathrm{kg}^{-1}$ ar seco), proposta por Albright (1990):

$$
\mathrm{H}=1,006 \mathrm{Ts}+\mathrm{W}(2501+1,805 \mathrm{Ts})
$$

em que:

$T_{S}$ - temperatura de bulbo seco $\left({ }^{\circ} \mathrm{C}\right)$

$\mathrm{W}$ - razão de mistura ( $\mathrm{kg}$ vapor d'água.kg ar seco-1)

A análise dos parâmetros zootécnicos dos animais foi realizada adotando-se as metodologias convencionais para o registro de ganho de peso e mortalidade. Os parâmetros avaliados foram:

\section{Ganho de peso}

Os leitões foram pesados no dia do nascimento e no desmame. O ganho de peso diário (GPD) foi obtido dividindose o ganho total de peso pelo número de dias em que os animais permaneceram na maternidade, de acordo com a equação apresentada abaixo:

$$
\mathrm{GPD}=\frac{\mathrm{GPP}}{\mathrm{ND}}
$$

em que:

GPD - ganho de peso diário $\left(\mathrm{kg} \mathrm{dia}^{-1}\right)$

GPP - ganho de peso do período $(\mathrm{kg})$

$\mathrm{ND}$ - número de dias que os animais permaneceram na maternidade

\section{Mortalidade}

Foi registrado o número diário de óbitos durante o período em que os animais permaneceram na maternidade.

A realização da análise técnico-econômica foi realizada registrando-se o consumo de energia $(\mathrm{kWh})$ dos diferentes sistemas de aquecimento, com o auxílio de medidores (relógios), verificando-se o consumo total no período em que os leitões permaneceram na maternidade (18 dias), em função do manejo diferenciado em cada etapa estudada. A relação custo benefício foi determinada de acordo com o custo do $\mathrm{kWh}$ e o ganho de peso do animal, associando-o com o preço pago pelo peso vivo do leitão. 
Utilizou-se o delineamento em blocos casualizados (DBC), adotando-se 4 tratamentos e 18 blocos, tendo-se em conta os blocos com os números de observações diárias estudadas. As médias das variáveis resposta dos microambientes foram comparadas pelo teste de Tukey $(\mathrm{P}<0,05)$. Toda a análise estatística foi realizada por meio do programa estatístico Statistical Analysis System (SAS, 1992).

Realizou-se uma análise de regressão para comparação entre as temperaturas externas (abrigo meteorológico) em função da temperatura na sala da maternidade.

\section{RESULTADOS E DISCUSSÃO}

Para os dados referentes à temperatura na sala da maternidade e no abrigo meteorológico (ambiente externo), foram ajustadas equações utilizando-se análise de regressão que envolvia valores médios horários da temperatura externa em função da temperatura na sala da maternidade. As curvas de ajuste 1:1 apresentaram variação linear e valor de $\mathrm{R}^{2}(0,38)$, significativo a $1 \%$ de probabilidade pelo teste $\mathrm{F}$, verificando-se valores médios de temperatura de aproximadamente $31,4 \%$, superiores na sala da maternidade (Figura 2). Essa variação foi observada justamente pelo fato das baixas temperaturas externas, considerando-se que nessa situação o manejo das cortinas era realizado de forma a isolar o meio interno do externo, verificando-se maior controle das flutuações térmicas e, conseqüentemente, temperatura maior. $\mathrm{O}$ manejo correto das cortinas laterais permitia o maior controle no interior da instalação, evitando as altas variações da amplitude térmica e apresentando valor médio da ordem de $3{ }^{\circ} \mathrm{C}$.

A comparação entre os tratamentos apresentados na Tabela 1, é resultado médio diário das variáveis resposta dos microambientes estudados, abrigos escamoteadores e seus respectivos sistemas de aquecimento. Verificou-se que todos os tratamentos apresentaram diferenças significativas para temperatura de bulbo seco (Ts), temperatura de globo negro (Tg) e umidade relativa do ar (UR).

A temperatura de bulbo seco mostrou variação significativa entre os 4 tratamentos estudados. Por meio de valores médios pôde-se verificar, no ambiente com piso térmico, menor

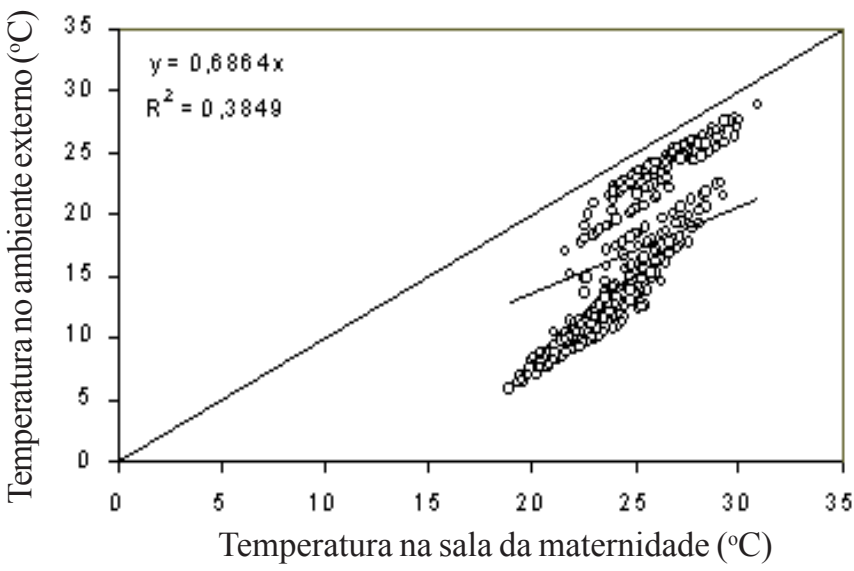

Figura 2. Representação da análise de regressão entre temperatura na sala da maternidade e no abrigo meteorológico (ambiente externo), envolvendo todos os dados coletados temperatura no microclima gerado, seguido da lâmpada incandescente, resistência elétrica e lâmpada infravermelha, respectivamente. De forma geral, pode-se dizer que, para a zona de conforto térmico para os leitões na fase da maternidade, os três primeiros tratamentos são recomendados, porém se deve lembrar que esses dados são valores médios diários.

Tabela 1. Valores médios das variáveis ambientais observadas durante a permanência dos leitões na maternidade*

\begin{tabular}{lccc}
\hline \multirow{2}{*}{ Tratamentos } & \multicolumn{3}{c}{ Variáveis (fase de inverno) } \\
\cline { 2 - 4 } & Ts $\left({ }^{\circ} \mathrm{C}\right)$ & $\operatorname{Tg}\left({ }^{\circ} \mathrm{C}\right)$ & UR $(\%)$ \\
\hline Piso térmico & $28,7 \mathrm{~d}$ & $28,9 \mathrm{c}$ & $60,5 \mathrm{a}$ \\
Lâmpada incandescente & $32,2 \mathrm{c}$ & $32,8 \mathrm{~b}$ & $48,9 \mathrm{c}$ \\
Resistência elétrica & $32,9 \mathrm{~b}$ & $32,9 \mathrm{~b}$ & $50,6 \mathrm{~b}$ \\
Lâmpada infravermelha & $40,4 \mathrm{a}$ & $41,8 \mathrm{a}$ & $31,7 \mathrm{~d}$ \\
\hline
\end{tabular}

* Ts - temperatura de bulbo seco, Tg - temperatura de globo negro, UR - umidade relativa do ar Valores médios com letras diferentes na mesma coluna, diferem estatisticamente pelo teste de Tukey, $\mathrm{P}<0,05$

A Figura 3A aponta a influência do efeito dos diferentes sistemas de aquecimento na temperatura interna dos abrigos escamoteadores, condições em que se verifica que o aquecimento proporcionado aos leitões pela lâmpada incandescente e resistência elétrica, se aproximou mais da faixa de conforto térmico dos animais, 32 a $28^{\circ} \mathrm{C}$ (Silva, 1999). $\mathrm{O}$ tratamento piso térmico esteve abaixo da condição recomendada, principalmente na $1^{\text {a }}$ semana de vida dos animais.

Com relação à lâmpada infravermelha, os dados referentes à temperatura no interior do abrigo estiveram, em média, sempre acima da condição ideal, durante toda a fase experimental, ultrapassando o valor da temperatura crítica superior (TCS) de 38 a $33^{\circ} \mathrm{C}$ (Mount, 1968; Curtis, 1983).

Constata-se que esta tendência diferiu dos dados de verão, principalmente com relação à variação da temperatura externa, que teve seus valores bem inferiores nesse período. Em função disso, a eficiência dos tratamentos foi diferenciada quando comparados com períodos mais quentes.

Validando as informações obtidas pela variação da temperatura média diária nos tratamentos avaliados observase, na Figura 3B, a variação das temperaturas mínimas diárias, cujos resultados demonstram que a condição de conforto nas $1^{\text {a }}$ e $2^{\text {a }}$ semanas de vida dos animais, é atendida pelos tratamentos lâmpada incandescente e resistência elétrica. Para o tratamento piso térmico, a disponibilidade de energia térmica proporcionada pela fonte de aquecimento, não foi suficiente para as duas semanas iniciais, contemplando as exigências dos animais apenas na $3^{\mathrm{a}}$ semana.

O tratamento equipado com lâmpada infravermelha apresentou, praticamente, a mesma resposta, mostrando-se sempre acima da condição adequada, atingindo valores de TCS de $38^{\circ} \mathrm{C}$.

Para uma visualização melhor dos resultados, adotou-se a metodologia da adoção dos dias críticos para essa condição de produção, ou seja, períodos mais frios são considerados dias críticos, para leitões. Portanto, foram selecionados os dias com menor entalpia em cada semana da fase de crescimento dos animais, durante a fase da maternidade, segundo metodologia proposta por Moura et al. (1997). 
A.

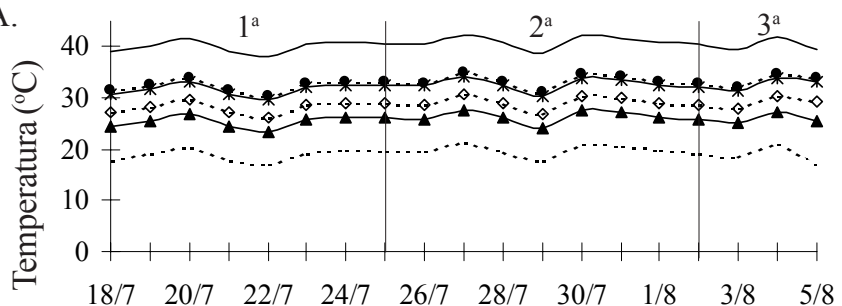

B.

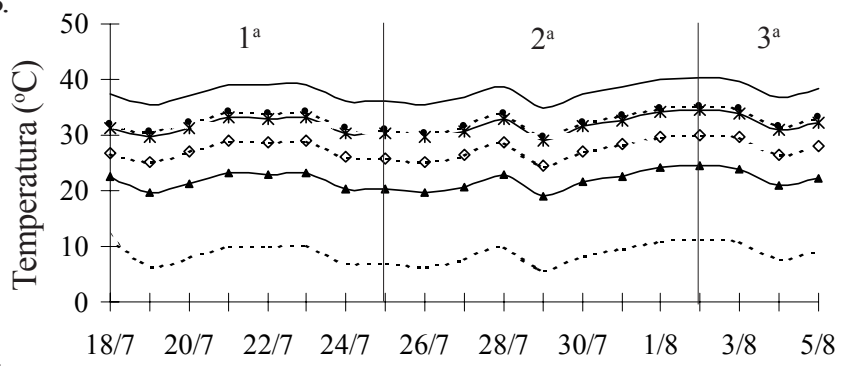

C.

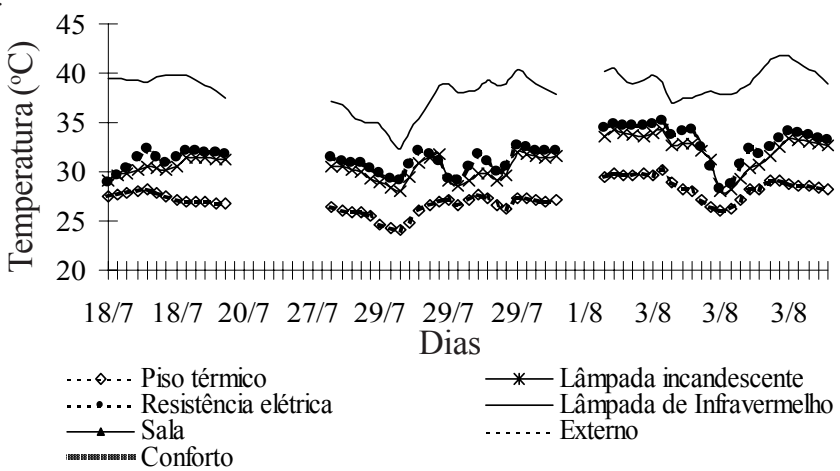

Figura 3. Variação da temperatura média diária (A) mínima diária

(B) e para os dias de menor entalpia (C) nos diferentes tratamentos na sala da maternidade e no abrigo meteorológico (ambiente externo)

Os sistemas de aquecimento mais adequados, mesmo para os dias selecionados, dias de menor entalpia, foram lâmpada incandescente e resistência elétrica (Figura 3C). Para os outros tratamentos, a temperatura se apresentou acima (lâmpada infravermelha), e abaixo (piso térmico), das condições de conforto térmico dos leitões, 32 a $28^{\circ} \mathrm{C}$.

Com relação aos dados referentes à temperatura de globo negro os valores registrados para os diferentes sistemas de aquecimento estudados apresentaram o mesmo comportamento da Ts, devido à pequena variação mostrada entre as respectivas variáveis ambientais.

A variação da umidade relativa do ar no interior dos escamoteadores apresentou diferenças significativas, sobretudo no abrigo equipado com lâmpada infravermelha que, além de promover altas temperaturas no interior do abrigo, reduziu significativamente a umidade relativa no seu interior, pois o volume de ar se contrai e/ou expande com a variação da temperatura. Esta variação de volume impõe um limite à quantidade de vapor d'água que pode ser retida pelo volume de ar, ou seja, quanto maior a temperatura maior a quantidade máxima saturante de vapor d'água. Desta forma, verificam-se baixos valores de UR para tal situação.

Com relação ao tratamento com piso térmico, a energia térmica radiante proveniente do piso, não foi suficiente para promover redução da UR nos níveis verificados nos demais tratamentos (Figura 4), apresentando valor mais próximo do ideal, entre 60 e 70\% (Nääs, 1989; Silva, 1999).

As médias dos índices de ITGU, CTR e H, correspondentes ao período experimental em função dos tratamentos adotados, estão apresentadas na Tabela 2.

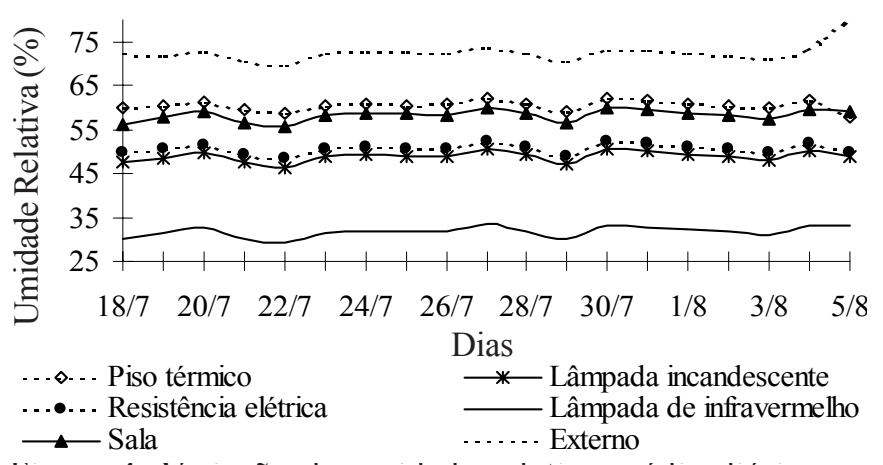

Figura 4. Variação da umidade relativa média diária nos diferentes tratamentos na sala da maternidade e no abrigo meteorológico (ambiente externo)

O índice de temperatura de globo e umidade (ITGU) apresentou valores médios para resistência elétrica, lâmpada incandescente e lâmpada infravermelha, que não diferiram estatisticamente. O menor valor médio de ITGU foi verificado para o tratamento piso térmico, diferindo estatisticamente quando comparado com os demais (Tabela 2).

Com relação ao ITGU e se considerando o dia de menor entalpia, nas $1^{\text {a }}, 2^{\mathrm{a}}$ e $3^{\mathrm{a}}$ semanas avaliadas; verifica-se, na Figura $5 \mathrm{~A}$, que os abrigos equipados com lâmpada incandescente e resistência elétrica foram aqueles que apresentaram valores mais próximos do ideal, 82 a 84 (Necoechea, 1986), para os três dias críticos, dias de menor entalpia, estudados. Os abrigos equipados com lâmpada infravermelha e piso térmico apresentaram valores acima e abaixo do recomendado, respectivamente.

Observando-se os valores médios da CTR, verificam-se diferenças significativas para lâmpada infravermelha, resistência elétrica, lâmpada incandescente e piso térmico, respectivamente (Tabela 2). O maior valor de CTR foi observado para o tratamento lâmpada infravermelha, verificando-se valores superiores à energia radiante média recomendada, de aproximadamente $450 \mathrm{~W} \mathrm{~m}^{-2}$ (Baêta \& Souza, 1997).

O valor médio da CTR apresentada pelo piso térmico de 473 $\mathrm{W} \mathrm{m}{ }^{-2}$, foi aquele que mais se aproximou da condição recomendada. Além da fonte de aquecimento, atribuem-se os altos valores de CTR no interior dos abrigos, por se tratar de um ambiente pequeno, vedado, com pequena velocidade de ar

Tabela 2. Valores médios dos índices de conforto, ITGU, CTR e $\mathrm{H}$ durante a permanência dos leitões na maternidade*

\begin{tabular}{lccc}
\hline & \multicolumn{3}{c}{ Variáveis (Fase de inverno) } \\
\cline { 2 - 4 } Tratamentos & ITGU & CTR & H \\
\hline Piso térmico & $77,5 \mathrm{~b}$ & $473,0 \mathrm{~d}$ & $68,9 \mathrm{~d}$ \\
Lâmpada incandescente & $81,3 \mathrm{a}$ & $493,2 \mathrm{c}$ & $72,1 \mathrm{c}$ \\
Resistência elétrica & $82,3 \mathrm{a}$ & $496,5 \mathrm{~b}$ & $75,9 \mathrm{~b}$ \\
Lâmpada infravermelho & $81,1 \mathrm{a}$ & $554,6 \mathrm{a}$ & $81,1 \mathrm{a}$ \\
\hline * Valores médios com letras diferentes, na mesma coluna, diferem estatisticamente pelo pelo Teste \\
de Tukey, P< 0,05
\end{tabular}




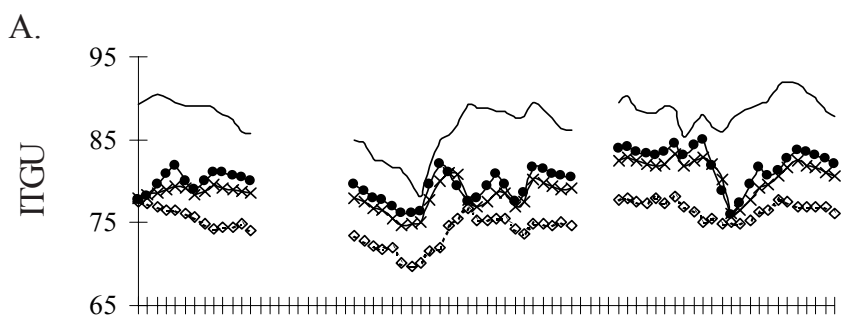

B.

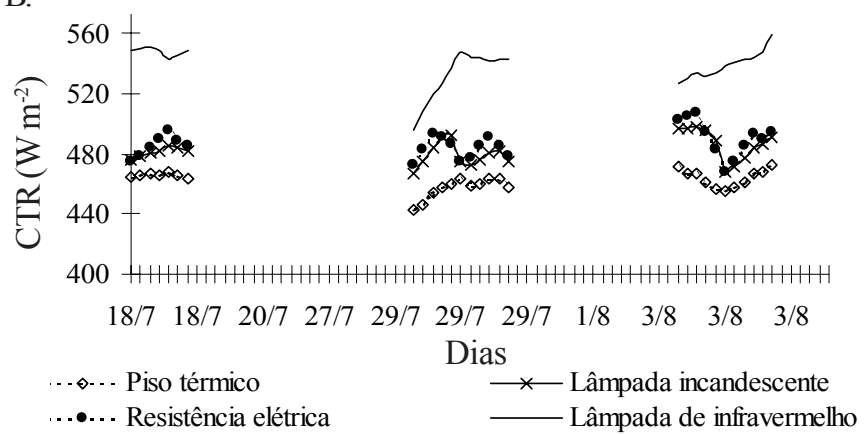

Figura 5. Variação do índice de temperatura de globo e umidade - ITGU (A) e carga térmica radiante - CTR (B) para os dias de menor entalpia nos diferentes tratamentos avaliados

$\left(0,03 \mathrm{~m} \mathrm{~s}^{-1}\right)$. Considera-se que a CTR é influenciada pelo efeito convectivo, juntamente com a temperatura média radiante. Para os outros sistemas de aquecimento, nota-se que todos os tratamentos excederam a condição recomendada para os animais, apresentando valores médios da ordem de 493,2 , 496,5 e 554,6 W m ${ }^{-2}$ para lâmpada incandescente, resistência elétrica e lâmpada infravermelha, respectivamente (Figura 5B).

Os valores médios da entalpia $(\mathrm{H})$ apresentam resultados que apontam diferenças estatísticas entre todos os tratamentos. O maior valor verificado foi para o abrigo equipado com lâmpada infravermelha, resistência elétrica, lâmpada incandescente e piso térmico, respectivamente, expressando a quantidade de energia interna da parcela de ar, nos microambientes avaliados em relação à soma de suas componentes, de uma mistura de ar seco e vapor d'água, levando-se em consideração a Ts $\left({ }^{\circ} \mathrm{C}\right)$ e a razão de mistura em $\mathrm{kg}$ de vapor d'água $/ \mathrm{kg}$ de ar seco.

Pode-se verificar, na Figura 6A, que a variação entálpica nos tratamentos adotados para $1^{\mathrm{a}}$ semana experimental, não atingiu o valor ideal de $90,2 \mathrm{~kJ} \mathrm{~kg}$ ar $\mathrm{seco}^{-1}$ em nenhum dos tratamentos avaliados, sendo que o sistema de aquecimento que mais se aproximou do valor recomendado foi a lâmpada infravermelha. Para a $2^{\mathrm{a}}$ semana, o tratamento mais eficiente foi a resistência elétrica, com valores mais próximos de $81,6 \mathrm{~kJ} \mathrm{~kg}$ ar $\operatorname{seco}^{-1}$. $\mathrm{Na}$ última semana, os tratamentos lâmpada incandescente e resistência elétrica foram os que melhor se ajustaram à condição ideal, de $73,8 \mathrm{~kJ} \mathrm{~kg}$ ar $\mathrm{seco}^{-1}$ e o piso térmico esteve sempre abaixo da condição entálpica necessária ao conforto dos leitões.

As aproximações dos valores de entalpia recomendada para os animais, foram calculados com base nas condições mínimas de conforto dos animais, 32,30 e $28^{\circ} \mathrm{C}$, e umidade relativa de $70 \%$, citadas por Silva (1999), para as primeira, segunda e terceira semanas de vida dos leitões, respectivamente.

Para segurança das informações citadas acima, procurouse representar as variações mínimas de entalpia verificadas nesta fase, como se pode observar na Figura 6B. Consideram- se as condições mínimas de entalpia com o cálculo dessa grandeza psicrométrica, utilizando-se a temperatura mínima diária.

Considerando-se a quantidade de calor existente na massa de ar seco dentro de cada abrigo escamoteador, pode-se dizer, pelos dados apresentados na Figura 6B, que nenhum dos tratamentos estudados foi eficiente no acondicionamento dos animais, durante as duas primeiras semanas críticas de vida dos leitões, porém para a $3^{\text {a }}$ semana os sistemas de aquecimento, lâmpada incandescente e resistência elétrica, atenderam efetivamente à condição mínima de conforto dos animais.

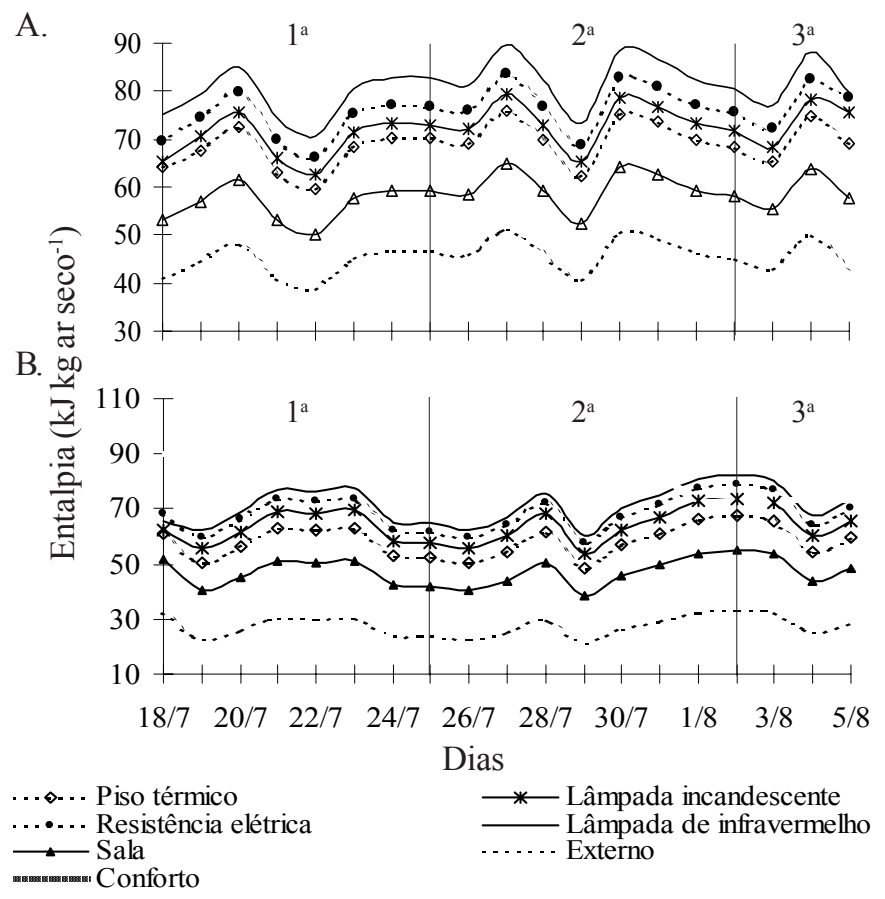

Figura 6. Variação da entalpia média diária (A) e mínima diária

(B) nos diferentes tratamentos na sala da maternidade e no abrigo meteorológico (ambiente externo)

Com relação ao ganho de peso diário dos leitões observase, na Figura 7, que todos os tratamentos avaliados atingiram os índices desejados, ou seja, para todos os sistemas de aquecimento os leitões superaram um ganho de peso diário de $0,240 \mathrm{~kg}$, para leitões nascidos com um peso médio de $1,8 \mathrm{~kg}$ e um desmame aos 19 dias, com um peso médio de 6,4 kg (Mores et al., 1998).

$\mathrm{O}$ abrigo equipado com piso térmico foi aquele que apresentou os melhores resultados para ganho de peso diário de $0,303 \mathrm{~kg} \mathrm{dia}^{-1}$, seguido da lâmpada infravermelha, lâmpada incandescente e resistência elétrica, não se verificando influência direta dos tratamentos para GPD $\left(\mathrm{kg} \mathrm{d}^{-1}\right)$; uma tendência na relação comportamento animal $\mathrm{x}$ condicionamento térmico ambiental x desempenho dos leitões, pode ser explicada pelo fato do piso térmico proporcionar um fluxo de calor condutivo e, portanto, mais eficiente às trocas de calor, atingindo equilíbrio na faixa de 30 a $32{ }^{\circ} \mathrm{C}$, faixa de aquecimento do piso. Desta forma, para certeza da informação, haveria a necessidade de um estudo comportamental, já que o sistema de aquecimento em questão não condicionou o abrigo como 


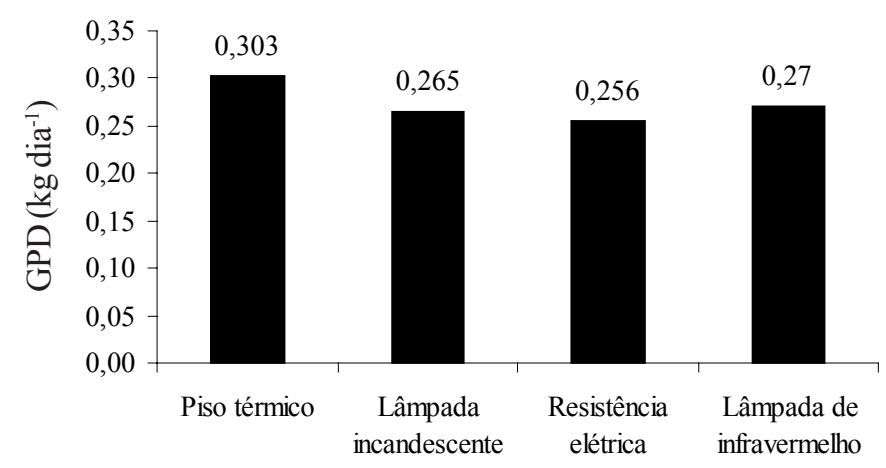

Figura 7. Ganho de peso $\left(\mathrm{kg} \mathrm{d}^{-1}\right)$ dos leitões submetidos aos diferentes sistemas de aquecimento

um todo e os sensores para o registro das temperaturas estavam instalados a uma altura de $0,55 \mathrm{~m}$ do piso.

Não se contabilizou nenhum óbito entre os leitões que utilizaram os abrigos com os respectivos tratamentos estudados, apesar da média registrada na sala da maternidade ser de aproximadamente $5 \%$, considerando-se dentro de um valor médio aceitável, especialmente se relacionados com o alto número de leitões nascidos por parto, média de 11,9 (Mores et al., 1998).

O consumo de energia dos diferentes sistemas de aquecimento pode ser verificado na Figura 8. Observa-se que

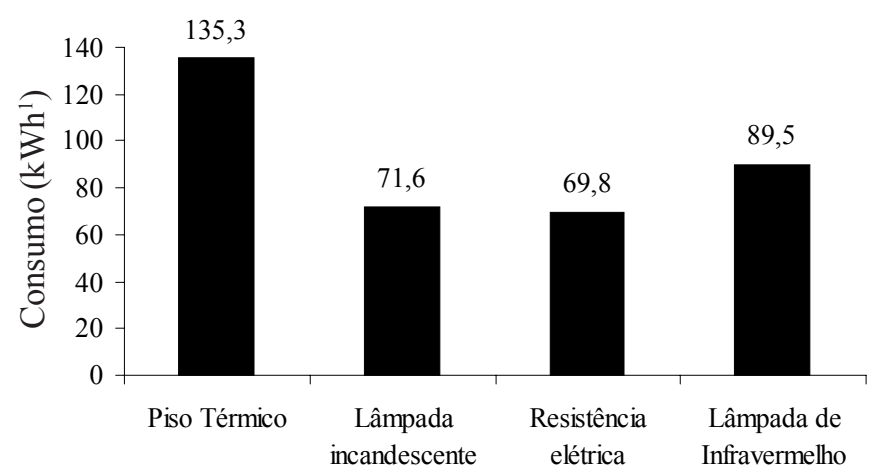

Figura 8. Consumo de energia elétrica $(\mathrm{kWh})$ dos diferentes sistemas de aquecimento

o abrigo equipado com piso térmico apresentou consumo superior de energia elétrica, valores da ordem de, 48, 49 e 34\%, em relação à lâmpada incandescente, resistência elétrica $\mathrm{e}$ lâmpada infravermelha, respectivamente.

Verifica-se, na Tabela 3, o custo envolvido em relação ao consumo de energia elétrica dos sistemas de aquecimento estudados, considerando-se tarifa cobrada pela concessionária de $\mathrm{R} \$ 0,138270 \mathrm{kWh}^{-1}$, para zona rural (CPFL - 5/11/02). Para efeito de comparação, também são apresentados os valores de rendimento e ganho de peso dos animais em relação aos diferentes sistemas de aquecimento adotados, considerandose o $\mathrm{kg}$ do peso vivo de leitões em torno de $\mathrm{R} \$ 8,00$, de acordo com a Associação Brasileira de Criadores de Suínos (ABCS), cotação do dia 13/10/2002 (Porkworld, 2002).

$\mathrm{O}$ valor do rendimento foi calculado associando-se o preço pago pelo $\mathrm{kg}$ do peso vivo de leitões e o peso $(\mathrm{kg})$ dos leitões no desmame, subtraindo-se do custo com energia elétrica.
Tabela 3. Valor total (R\$), pago pelo consumo de energia elétrica $(\mathrm{kWh})$, dos diferentes sistemas de aquecimento avaliados e o seu rendimento $(\mathrm{R} \$)$ para o período estudado

\begin{tabular}{l|cccc}
\hline & \multicolumn{4}{c}{ Tratamentos } \\
\cline { 2 - 5 } & PT & LI & RE & LV \\
\hline Consumo (kWh) & 135,3 & 71,6 & 69,8 & 89,5 \\
Custo (R\$) & 18,71 & 9,90 & 9,65 & 12,41 \\
Pd (kg) & 5,76 & 5,03 & 4,86 & 5,13 \\
Preço pago (R\$) & 46,10 & 40,24 & 38,90 & 41,00 \\
Rendimento (R\$) & 27,39 & 30,34 & 29,25 & 28,59 \\
\hline PT - piso térmico; LI - lâmpada incandescente; RE - resistência elétrica \\
LV - lâmpada infravermelha; Pd - peso total no o desmame
\end{tabular}

Verifica-se que, para o tratamento lâmpada incandescente, o valor de rendimento mostrou-se superior, em torno de $\mathrm{R} \$ 30,34$, cerca de $9,72 \%$ superior para o piso térmico, $3,6 \%$ para resistência elétrica e 5,76\% para lâmpada infravermelha.

Ante esses resultados, constata-se que os tratamentos resistência elétrica e lâmpada incandescente foram os mais viáveis economicamente, para o período de inverno, porém a utilização de termostato para o controle do acionamento das fontes de aquecimento é indispensável para promover maior economia de energia elétrica.

\section{CONCLUSÕES}

1. As variáveis ambientais apontam que o uso de aquecimento para os leitões no período de inverno é indispensável.

2. Em virtude das baixas temperaturas registradas nessa etapa, os sistemas de aquecimento que se mostraram mais adequados do ponto de vista térmico, foram lâmpada incandescente e resistência elétrica.

3. De acordo com a análise técnico-econômica realizada, verificou-se que o maior rendimento para o período estudado foi a lâmpada incandescente, $\mathrm{R} \$ 30,34$, seguido da resistência elétrica, lâmpada infravermelha e piso térmico, respectivamente.

\section{LITERATURA CITADA}

Albright, L.D. Environment control for animals and plants. St. Joseph: American Society of Agricultural Engineers Michigan. 1990.453p. ASAE Textbook, 4

Bäckström, L.; Curtis, S.E. Housing and environmental influences on production. In: Leman, A.D. (ed.) Diseases of swine. Ames: Iowa State University Press, 1981. p.737-753.

Baêta, F.C.; Souza, C.F. Ambiência em edificações rurais conforto animal. Viçosa: UFV, 1997. 246p.

Buffington, D.E.; Colazzo-Arocho, A.; Caton, G.H. Black globe humidity comfort index (BGHI) as comfort equation for dairy cows. Transaction of the ASAE, St. Joseph, v.24, n.4, p.711714. 1981.

Curtis, S.E. Environmental management in animal agriculture. Ames: Iowa State University Press, 1983. 409p.

D'Arce, R.D.; Teague, H.S.; Roller, W.L. Effect of short-term elevated dry-bulb and dew-point temperature on the cycling gilt. Journal Animal Science, Stanford, v.30, n.2, p.374-380, 1970. 
Esmay, M.L. Principles of animal environment. West Port: ABI, 1982.325p.

Mores, N.; Sobestiansky, J.; Wentz, I.; Moreno, A.M. Manejo do leitão do nascimento até o abate. In: Sobestiansky, J.; Wentz, I.; Silveira, P.R.S.; Sesti, L.A.C. (eds.) Suinocultura intensiva. Concórdia: Embrapa - CNPSA, 1998. p.135-161.

Mount, L.E. The climate physiology of the pig. Baltimore: Williams and Welkins. 1968. 271p.

Moura, D.J.; Nääs, I.A.; Silva, I.J.O.; Sevegnani, K.B.; Corria, M.E. The use of enthalpy as a thermal comfort index. In: Livestick environment, v.5, St. Joseph. Proceedings... St. Joseph: ASAE, 1997. v.1, p.242-248.

Nääs, I.A. Princípios de conforto térmico na produção animal. São Paulo: Ed. Ícone, 1989. 183p.

Necoechea, A.R. Doenças e meio ambiente. Suinocultura Industrial, São Paulo, v.8, n.8, p.13-26, 1986.

Perdomo, C.C.; Sobestiansky, J.; Oliveira, P.V.A.; Oliveira, J.A. Efeito de diferentes sistemas de aquecimento no desempenho de leitões. Concórdia: EMBRAPA - CNPSA, 1987. p.1-3. Comunicado Técnico, 122
Pereira, A.R.; Angelocci, L.R.; Sentelhas, P.C. Agrometeorologia: fundamento e aplicações práticas. Guaíba: Agropecuária, 2002.478p

Porkworld (ABCS) - www.porkworld.com.br. 18 nov. 2002.

Rossi, L.A.; Cardoso, P.E.R.; Beraldo, A.L. Desempenho de placas de argamassa de cimento e casca de arroz aquecidas por resistência elétrica. In: Congresso Brasileiro de Engenharia Agrícola, 31., Salvador, 2002. Anais... Salvador: SBEA, 2002.p.249-252.

SAS - Statistical Analysis System. Realease 6.08, (software). Cary: SAS Institute, 1992. 620p.

Silva, I.J.O. Qualidade do ambiente e instalações na produção industrial de suínos. In: Simpósio Internacional de Suinocultura. São Paulo, 1999. Anais. São Paulo: Gessuli, 1999.p.108-121.

Thompkins, E.C.; Heidenreich, C.J.; Stob, M. Effect of postbreeding thermal stress on embryonic mortality in swine. Journal Animal Science, Stanford, v.26, n.2, p.377-380, 1967. 